\title{
Influência do Cálcio na Calda de Pulverização sobre a Eficácia do Carfentrazone-Ethyl no Controle de Euphorbia heterophylla ${ }^{1}$
}

\author{
Influence of Calcium in the Spray Tank on the Efficacy of Carfentrazone-Ethyl \\ Euphorbia heterophylla Control
}

\begin{abstract}
CARVALHO, F.T. ${ }^{2}$, CAETANO, L. ${ }^{2}$, PERUCHI, M. ${ }^{3}$ e PALAZZO, R.R.B. ${ }^{3}$
RESUMO - Alguns herbicidas podem ter sua eficácia de controle das plantas daninhas diminuída quando o cálcio encontra-se presente na calda de pulverização. Sendo assim, o presente trabalho foi desenvolvido com o objetivo de estudar a influência do cálcio na eficácia do herbicida carfentrazone-ethyl aplicado em pós-emergência sobre plantas adultas de Euphorbia heterophylla. Foram conduzidos dois experimentos com as concentrações de cálcio variando de 30 a $240 \mathrm{ppm}$ e de 0 a $1.000 \mathrm{ppm}$ respectivamente em cada experimento. $\mathrm{O}$ delineamento experimental utilizado foi o de blocos ao acaso, com quatro repetições. Observouse que a eficácia do herbicida carfentrazone-ethyl não é afetada pela presença de cálcio em concentrações na calda de pulverização de até $1.000 \mathrm{ppm}$ e que, na dose de 30 g i.a.ha ${ }^{-1} \mathrm{o}$ herbicida é eficiente no controle de plantas adultas de E. heterophylla.
\end{abstract}

Palavras-chave: água, qualidade, herbicida.

\begin{abstract}
The efficacy of some herbicides can be reduced in the presence of calcium in the spray tank. This work was developed to study the influence of calcium on the efficacy of the herbicide carfentrazone-ethyl applied to Euphorbia heterophylla in late post-emergence. The research consisted of two experiments with the calcium concentrations varying from 30 to $240 \mathrm{ppm}$ and from 0 to $1000 \mathrm{ppm}$ in each experiment, respectively. The experimental design was a complete randomized block with four replications. Carfentrazone-ethyl efficacy for weed control was not affected by calcium in the spray tank even at $1000 \mathrm{ppm}$. The herbicide was also found to be in the control of $\boldsymbol{E}$. heterophylla at late post-emergence stage, in the dose of $30 \mathrm{~g}$ i.a. $h \mathrm{a}^{-1}$.
\end{abstract}

Key words: water, quality, herbicide.

\section{INTRODUÇÃO}

A eficiência dos herbicidas no controle das plantas daninhas pode ser influenciada por uma série de fatores, entre eles a qualidade da água nas pulverizações.
A utilização de água limpa, livre de impurezas e/ou elementos minerais, que podem prejudicar o desempenho dos defensivos, nem sempre é possivel. Portanto, é interessante saber até que ponto a qualidade da água pode comprometer a eficácia de alguns produtos.

\footnotetext{
Recebido para publicação em 10/11/2000 e na forma revisada em 23/2/2001.

2 Profs. Drs., FEIS-UNESP, Av. Brasil, 56, Cx. P. 31, 15385-000 Ilha Solteira-SP; ${ }^{3}$ Graduandos de Agronomia da FEIS-
} UNESP. 
Segundo Ramos \& Durigan (1998), a presença de alguns elementos minerais na água de pulverização é mais prejudicial do que a presença de argilas, principalmente nas condições brasileiras, em que as argilas (caulinitas) possuem baixo poder de adsorção. Nos EUA, Sprankle et al. (1975 a, b) verificaram que argilas saturadas com $\mathrm{Fe}^{3+}, \mathrm{Al}^{3+}, \mathrm{Ca}^{2+} \mathrm{e} \mathrm{Na}^{+}$adsorvem significativamente mais glyphosate do que as argilas puras.

Sprankle et al. (1975 a, b) explicam que os elementos minerais podem ser classificados de acordo com a sua capacidade de desativação dos agroquímicos. Dessa forma, o ferro, o alumínio, o cálcio e o magnésio possuem de médio a alto poder de desativação, e o sódio, baixo. Entretanto, deve-se considerar a concentração com que os elementos podem ocorrer na calda. De acordo com Monsanto (1979) o Fe, o Zn, o $\mathrm{Al}$ e o Ca são os cátions que mais prejudicam a ação do glyphosate.

O cálcio é um elemento freqüentemente encontrado nas análises de água. Sua concentração natural varia de 0 a 1.000 ppm, nas diferentes regiões do Brasil, podendo ser maior (Monsanto, 1979). O antagonismo causado por esse elemento na ação de herbicidas depende de sua concentração e das características do produto. Gazziero et al. (1997) explicam que concentrações acima de 120 ppm de cálcio prejudicam o desempenho do herbicida glyphosate, e aquelas acima de 200 ppm, o do herbicida sulfosate.

Vários trabalhos científicos têm mostrado os efeitos prejudiciais do cálcio em alguns herbicidas. Deshpande \& Hall (1995), estudando os efeitos de cátions na eficácia do picloram, concluíram que a presença do cálcio aumentou a tolerância das plantas daninhas ao herbicida. Segundo os autores, o herbicida possui a característica de interagir com o cálcio, reduzindo sua absorção e translocação na planta.

Nalewaja et al. (1991) estudaram os efeitos de vários elementos químicos na eficácia do 2,4-D, aplicado no controle pós-emergente de plantas daninhas, e observaram que o cálcio, na forma de cloreto de cálcio, proporcionou efeito antagônico, prejudicando a eficiência do herbicida.

Shilling et al. (1990) observaram que a concentração de 72,5 ppm de Ca na calda, com
pH 8, reduziu em $18 \%$ a eficiência do glyphosate. Segundo Mervosh \& Balke (1991), na faixa de $\mathrm{pH}$ de 5 a 8, que é a mais comum nas aplicações de herbicidas, o poder de desativação do herbicida pelo cálcio é maior, se comparado com $\mathrm{pH}$ mais ácido. Monsanto (1979) explica que o $\mathrm{pH}$ menor reduz o poder de desativação do cálcio.

Phillips (1975) e Stahlman \& Phillips (1979) observaram que os efeitos negativos do cálcio na eficiência do glyphosate foram superados pela redução do volume de calda a níveis inferiores a $187 \mathrm{~L} \mathrm{ha}^{-1}$.

Buhler \& Burnside (1983), trabalhando com cloreto de cálcio, estudaram a influência do cátion na ação do glyphosate e observaram que concentrações menores que $28 \mathrm{ppm}$ de cálcio não afetam o desempenho do herbicida. O maior prejuízo foi observado a $232 \mathrm{ppm}$ de cálcio.

A presença de cátions nas águas de pulverização possui tanta importância que existem no mercado adjuvantes que liberam hidroxilas na solução, seqüestrando os cátions que interferem na funcionalidade química dos produtos, particularmente para o herbicida glyphosate.

Alguns herbicidas, portanto, podem ser desativados ou ter sua eficiência diminuída devido à presença do cálcio na água de pulverização. Dessa forma, são importantes os estudos que mostram quais são estes produtos e em que concentrações do elemento eles são afetados.

Este trabalho constou de dois experimentos de campo desenvolvidos com o objetivo de estudar a influência do cálcio na eficácia do herbicida carfentrazone-ethyl aplicado em pósemergência.

\section{MATERIAL E MÉTODOS}

O trabalho constou de dois experimentos, que foram conduzidos, respectivamente, nos períodos de dezembro de 1999 a janeiro de 2000 e de fevereiro a março de 2000, na Fazenda de Ensino e Pesquisa (FEP) da FEIS-UNESP, situada a $20^{\circ} 22^{\prime}$ de latitude sul, $51^{\circ} 22^{\prime}$ de longitude oeste e 335 metros de altitude e localizada no município de Selvíria-MS, enquadrada em região de cerrado, no sudeste do Mato 
Grosso do Sul. O solo da área experimental é classificado como Latossolo Vermelho-Escuro textura argilosa, com 38\% de argila.

O trabalho foi instalado em uma área naturalmente infestada de Euphorbia heteropylla, que se encontrava em fase de florescimento, com 0,30 a 0,40 m de altura, cobrindo $90 \%$ da superfície do solo, na ocasião das aplicações dos tratamentos

Os tratamentos utilizados nos experimentos estão apresentados na Tabela 1 . O herbicida utilizado possui a marca comercial Aurora $400 \mathrm{CE}$; nome comum: carfentrazone-ethyl; grupo químico: aril triazolinonas; formulação: concentrado emulsionável; e concentração do ingrediente ativo: $400 \mathrm{~g} \mathrm{~L}^{-1}$.

O delineamento utilizado nos experimentos foi o de blocos ao acaso. O experimento 1 foi desenvolvido com nove tratamentos e quatro repetições, com parcelas de $12 \mathrm{~m}^{2}$ ( 3 x $\left.4 \mathrm{~m}\right)$. O experimento 2 foi desenvolvido com onze tratamentos e quatro repetições, com parcelas de $10 \mathrm{~m}^{2}(5 \times 2 \mathrm{~m})$. Para interpretação estatística dos resultados, os dados foram submetidos à análise de regressão polinomial.

As aplicações dos tratamentos foram feitas com um pulverizador costal pressurizado $\left(\mathrm{CO}_{2}\right)$, com pressão constante de $316,46 \mathrm{Kpa}$
(45 $\mathrm{lb} \mathrm{pol}^{-2}$ ), provido de tanque com capacidade de dois litros (garrafas descartáveis) e com barra equipada com quatro bicos do tipo leque, marca Teejet 110.03 (XR), espaçados de 0,5 m. A altura de aplicação foi de $0,5 \mathrm{~m}$ em relação ao alvo, e o volume de calda, de 200 litros por hectare. A calda foi preparada utilizando-se água destilada com cálcio diluído em diferentes concentrações, conforme o tratamento.

As aplicações foram feitas em pós-emergência das plantas de Euphorbia heterophylla. As condições edafoclimáticas no momento das aplicações estão apresentadas na Tabela 2.

A eficiência do herbicida no controle da planta daninha foi avaliada aos 6, 15 (experimento 1) e 25 dias (experimento 2) após a aplicação (DAA). Utilizou-se uma escala visual, em que $0 \%=$ nenhum controle e $100 \%=$ controle total das plantas daninhas. Considerouse como eficiente o controle superior a $80 \%$.

Com relação à fórmula de cálcio utilizada, segundo Monsanto (1979), existem três formas naturais de ocorrência de cálcio na água: o carbonato de cálcio $\left[\mathrm{Ca}\left(\mathrm{CO}_{3}\right)_{2}\right]$, o sulfato de cálcio $\left(\mathrm{CaSO}_{4}\right)$ e o cloreto de cálcio $\left[\mathrm{Ca}(\mathrm{Cl})_{2}\right]$. Neste trabalho foi utilizado o cloreto de cálcio, devido às suas características de altíssima solubilidade e freqüência na água das mais diferentes regiões.

Tabela 1 - Tratamentos utilizados nos experimentos. FEP - Selvíria-MS (99/00)

\begin{tabular}{|c|c|c|c|}
\hline \multirow{2}{*}{ 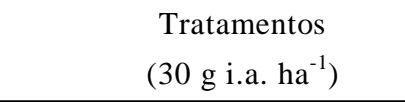 } & \multirow{2}{*}{ Experimento } & \multicolumn{2}{|c|}{ Concentração de Ca na calda (ppm) } \\
\hline & & Experimento 1 & Experimento 2 \\
\hline 1- testemunha sem herbicida & 1 e 2 & -- & -- \\
\hline 2- carfentrazone-ethyl* & 1 e 2 & 30 & 0 \\
\hline 3- carfentrazone-ethyl & 1 e 2 & 60 & 30 \\
\hline 4- carfentrazone-ethyl & 1 e 2 & 90 & 60 \\
\hline 5- carfentrazone-ethyl & 1 e 2 & 120 & 90 \\
\hline 6- carfentrazone-ethyl & 1 e 2 & 150 & 120 \\
\hline 7- carfentrazone-ethyl & 1 e 2 & 180 & 150 \\
\hline 8- carfentrazone-ethyl & 1 e 2 & 210 & 200 \\
\hline 9- carfentrazone-ethyl & 1 e 2 & 240 & 250 \\
\hline 10- carfentrazone-ethyl & 2 & -- & 500 \\
\hline 11- carfentrazone-ethyl & 2 & -- & 1.000 \\
\hline
\end{tabular}

* Aurora $400 \mathrm{CE}$. 
Tabela 2 - Condições edafoclimáticas no momento das aplicações. FEP - Selvíria-MS (2000)

\begin{tabular}{|c|c|c|c|c|c|c|}
\hline Experimento & Data & Horário & Solo & Temperatura de início & URar & Vento \\
\hline 1 & $16 / 12 / 99$ & $19 \mathrm{~h} 30$ às $20 \mathrm{~h} 30$ & Com umidade & $25^{\circ} \mathrm{C}$ & $70 \%$ & Nulo \\
\hline 2 & $16 / 02 / 00$ & $18 \mathrm{~h} 30$ às $19 \mathrm{~h} 45$ & Com umidade & $30^{\circ} \mathrm{C}$ & $73 \%$ & Nulo \\
\hline
\end{tabular}

Tabela 3 - Porcentagem média de controle de Euphorbia heterophylla nos experimentos. FEP - Selvíria-MS (2000)

\begin{tabular}{|c|c|c|c|c|c|c|c|}
\hline \multirow{3}{*}{ Tratamentos } & \multirow{2}{*}{\multicolumn{2}{|c|}{$\begin{array}{c}{[\mathrm{CA}]} \\
(\mathrm{em} \mathrm{ppm})\end{array}$}} & \multicolumn{5}{|c|}{$\%$ de Controle } \\
\hline & & & \multicolumn{2}{|c|}{ Experimento 1} & \multicolumn{3}{|c|}{ Experimento 2} \\
\hline & Exp. 1 & Exp. 2 & $6 \mathrm{DAA}$ & $15 \mathrm{DAA}$ & 6 DAA & 15 DAA & 25 DAA \\
\hline 1- sem herbicida & -- & -- & -- & -- & -- & -- & -- \\
\hline 2- com herbicida* & 30 & 0 & 85 & 87 & 83,8 & 85,0 & 86,2 \\
\hline 3- com herbicida & 60 & 30 & 82 & 85 & 83,8 & 84,5 & 86,0 \\
\hline 4- com herbicida & 90 & 60 & 84 & 86 & 85,8 & 87,0 & 87,5 \\
\hline 5- com herbicida & 120 & 90 & 80 & 84 & 86,2 & 88,0 & 89,0 \\
\hline 6- com herbicida & 150 & 120 & 84 & 86 & 83,8 & 84,5 & 85,0 \\
\hline 7- com herbicida & 180 & 150 & 84 & 85 & 86,2 & 87,0 & 87,5 \\
\hline 8- com herbicida & 210 & 200 & 78 & 82 & 82,5 & 85,0 & 85,0 \\
\hline 9- com herbicida & 240 & 250 & 85 & 86 & 82,5 & 83,0 & 85,0 \\
\hline 10-com herbicida & -- & 500 & -- & -- & 83,8 & 84,5 & 87,5 \\
\hline 11-com herbicida & -- & 1000 & -- & -- & 82,5 & 85,0 & 87,5 \\
\hline \multicolumn{3}{|c|}{ Média Geral } & 82,75 & 85,12 & 84,08 & 85,35 & 86,75 \\
\hline \multicolumn{3}{|c|}{ F (regressão linear) } & $0,1469^{\mathrm{ns}}$ & $0,7897^{\mathrm{ns}}$ & $0,2682^{\mathrm{ns}}$ & $0,1065^{\mathrm{ns}}$ & $0,0289^{\mathrm{ns}}$ \\
\hline \multicolumn{3}{|c|}{$\mathrm{F}$ (regressão 2 grau ) } & $1,7587^{\mathrm{ns}}$ & $1,1115^{\mathrm{ns}}$ & $0,0112^{\mathrm{ns}}$ & $0,1296^{\mathrm{ns}}$ & $0,1713^{\mathrm{ns}}$ \\
\hline \multicolumn{3}{|c|}{ F (regressão 3ำ grau ) } & $0,3095^{\mathrm{ns}}$ & $0,9064^{\mathrm{ns}}$ & $0,0003^{\mathrm{ns}}$ & $0,0403^{\mathrm{ns}}$ & $0,2557^{\mathrm{ns}}$ \\
\hline \multicolumn{3}{|l|}{$\mathrm{CV}$} & 5,13 & 3,98 & 9,46 & 7,70 & 6,94 \\
\hline
\end{tabular}

DAA $=$ dias pós a aplicação dos herbicidas.

$*$ herbicida $=$ carfentrazone-ethyl $\left(30 \mathrm{~g}\right.$ i.a. ha $\left.^{-1}\right)$.

A amostra-padrão foi preparada diluindose $\mathrm{Ca}(\mathrm{Cl})_{2}$ em água destilada, em concentrações necessárias para formar 20 litros de soluções com 240 ppm (experimento 1) e 1.000 ppm (experimento 2) de cálcio, correspondentes aos tratamentos com a maior concentração do elemento. Os tratamentos foram preparados diluindo-se a amostra-padrão para as concentrações correspondentes.

\section{RESULTADOS E DISCUSSÃO}

Os dados médios de porcentagem de controle de Euphorbia heterophylla estão contidos na Tabela 3. Observa-se que os tratamentos foram eficientes e semelhantes entre si no controle de E. heterophylla, independentemente da concentração de cálcio utilizada na calda.

Os resultados obtidos sugerem que o cálcio não prejudica a ação do carfentrazone-ethyl, embora relatos de vários trabalhos tenham mostrado os efeitos sobre outros herbicidas, como o glyphosate (Phillips, 1975; Monsanto, 1979; Stahlman \& Phillips, 1979; Buhler \& Burnside, 1983; Shilling et al., 1990; Mervosh \& Balke, 1991; Gazziero et al., 1997), o picloram (Deshpande \& Hall, 1995) e o 2,4-D (Nalewaja et al., 1991).

Provavelmente, o modo de ação do carfentrazone-ethyl, mais de contato do que sistêmico, impede que o cálcio prejudique o seu efeito. Isso fica mais evidente quando se observa que os citados herbicidas, prejudicados pelo 
cálcio, são sistêmicos e, conforme foi relatado, a translocação e, conseqüentemente, a ação deles é prejudicada pela presença do elemento na calda de pulverização.

Com relação à eficácia do herbicida carfentrazone-ethyl no controle de plantas adultas de E. heterophylla, observa-se que todos os tratamentos foram eficientes no controle da planta daninha, proporcionando níveis médios de controle superiores a $82 \%$, aos 15 DAA.

A boa eficácia do carfentrazone-ethyl, mesmo com níveis de cálcio na água de até 1.000 ppm, vem proporcionar mais uma opção de controle químico de plantas daninhas, em especial a E. heterophylla, a qual é relatada como muito importante em diversas áreas de cultivo (Forster \& Alves, 1976; Kissmann, 1976; Gelmini \& Diehl, 1983). Aliada a esse fato, a opção da utilização do carfentrazone-ethyl em plantio direto vem aumentar a viabilização dessa prática, principalmente em áreas onde esta planta daninha é problemática.

Em decorrência dos resultados, concluiuse que o herbicida carfentrazone-ethyl não é prejudicado pela presença de cálcio na calda de pulverização em concentrações de até $1.000 \mathrm{ppm}$ e que o herbicida carfentrazoneethyl (30 g i.a.ha ${ }^{-1}$ ) é eficiente no controle de plantas adultas de Euphorbia heterophylla.

\section{AGRADECIMENTOS}

Ao técnico de laboratório Wanderley Baruffaldi, do Dep. de Físico-Química da FEISUNESP, pelo apoio na fase preparatória do experimento.

\section{LITERATURA CITADA}

BUHLER, D.D.; BURNSIDE, D.C Effect of water quality, carrier volume, and acid on glyphosate phytotoxicity. Weed Sci., v.31, n.2, p.163-169, 1983.

DESHPANDE, S.; HALL J.C. Comparison of flashinduced light-scattering transients and proton efflux from auxinic-herbicide resistant and susceptible wild mustard protoplasts: a possible role for calcium in mediating auxinic herbicide resistance. Biochim. Biophys., v. 1244, Issue 1-11, p.69-78, 1995.
FORSTER, R.; ALVES, A. Os herbicidas na lavoura da soja. A Granja, Porto Alegre, v.32, p.32-38, 1976.

GAZZIERO, D.L.P.; VOLL, E.; FOLONI, L.L. A qualidade da água e a aplicação de glyphosate e sulfosate. In: CONGRESSO BRASILEIRO DA CIÊNCIA DAS PLANTAS DANINHAS, 21, 1997, Caxambu. Resumos... Viçosa: BCPD, 1997. p.414.

GELMINI, G.A.; DIEHL, S.R.L. Controle de plantas daninhas na cultura da soja. Campinas: CATI, 1983. 23 p. (CATI. Boletim Técnico, 170).

KISSMANN, K.G. Invasoras não gramíneas em lavouras de soja no Brasil Meridional e possibilidade de controle com bentazon. São Paulo: Basf Brasileira, 1976. 10p. (mimeografado).

MERVOSH, T.L.; BALKE, N.E. Effects of calcium, magnesium and phosphate on glyphosate absorption by cultured plant cells. Weed Sci., v.39, n.3, p.347-353, 1991.

MONSANTO. A review of Roundup herbicide. I e II. Factors affecting performance. II. Mechanism of action. St. Louis, Monsanto, 1979. 46p.

NALEWAJA, J.D., WOZNICA, Z., MATYSIAK, R. 2,4$\mathrm{D}$ amine antagonism by salts. Weed Technol., v.5, p.873-880, 1991.

PHILLIPS, W.M. Glyphosate phytotoxicity as affected by carrier quality and application volume. In: NORTHEASTERN WEED CONTROL CONFERENCE, 30, 1975, Bridgeton. Proceedings... Bridgeton: 1975. p.115.

RAMOS, H.H.; DURIGAN, J.C. Efeitos da qualidade da água de pulverização sobre a eficácia de herbicidas aplicados em pós-emergência. Bragantia, v.57, n.2, s/p, 1998.

SHILLING, D.G. et al. Influence of surfactants and additives on phytotoxicity of glyphosate to torpedograss. J. Aquatic Plant Manag., v.28, p.23-27, 1990.

SPRANKLE, P.; MEGGITT, W.F.; PENNER, D. Rapid inactivation of glyphosate in the soil. Weed Sci., Champaign, v.23, n.3, p.224-228, 1975a.

SPRANKLE, P.; MEGGITT, W.F.; PENNER, D. Adsorption, mobility, and microbial degradation of glyphosate in the soil. Weed Sci., v.23, n.3, p.229-234, 1975b.

STAHLMAN, P.W.; PHILLIPS, W.M. Effects of water quality and spray volume on glyphosate phytotoxicity. Weed Sci., v.27, n.1, p.38-41, 1979. 